\title{
Is 'GOLD' standard for the management of COPD in clinical practice?
}

\author{
Barbara P Yawn \\ Olmsted Medical Center, Rochester, Minnesota, USA
}

\begin{tabular}{|c|c|}
\hline Citation & Yawn B. Is 'GOLD' standard for the management of COPD in clinical practice? Drugs in Context 2012: 212243. doi:10.7573/dic.212243 \\
\hline Provenance & Invited; externally peer reviewed \\
\hline Dates & Submitted: 10 September 2012; Accepted, subject to peer review: 14 September 2012; Published: 26 November 2012 \\
\hline Copyright & $\begin{array}{l}\text { (c) } 2012 \text { Yawn B. This is an open-access article distributed under the terms of the Creative Commons Attribution License (CC-BY-NC-ND 3.0) } \\
\text { which allows unrestricted sharing, copying and distribution for personal use provided it is properly attributed. Commercial use is not } \\
\text { permitted. }\end{array}$ \\
\hline Correspondence address & $\begin{array}{l}\text { Professor Barbara Yawn, Director of Research, Olmsted Medical Center, Rochester, Minnesota, USA Department of Family and Community } \\
\text { Health, University of Minnesota, USA }\end{array}$ \\
\hline Email & BYawn@olmmed.org \\
\hline Competing interests & $\begin{array}{l}\text { Novartis, investigator initiated research grant on COPD exacerbations; Boehringer Ingelheim/Pfizer, research funding for a randomized } \\
\text { controlled study on COPD screening }\end{array}$ \\
\hline Keywords & $\begin{array}{l}\text { chronic bronchitis, COPD, emphysema, exacerbations, FEV1, formoterol, FVC, GOLD, immunization, indacaterol, LABA, LAMA, LTRA, } \\
\text { methylxanthines, Respimat, roflumilast, SGRQ, tiotropium, TORCH, UPLIFT }\end{array}$ \\
\hline
\end{tabular}

\section{Introduction}

Chronic obstructive pulmonary disease (COPD) is a preventable and treatable but usually progressive obstructive lung disease most often associated with tobacco smoking in 'developed' countries and accentuated by exposure to biomass fuel smoke in 'developing' countries [1]. COPD affects more than 200 million people worldwide. It is the third leading cause of mortality in the USA [2], and is predicted to become the third most common cause of death worldwide by 2030 [3]. COPD is the 'umbrella' term for emphysema and chronic bronchitis. Emphysema is the abnormal permanent enlargement and destruction of the airspaces distal to the terminal bronchioles, and is a pathologic description that is often recognized by imaging. Chronic bronchitis is a syndrome defined as a chronic productive cough for 3 months in each of 2 successive years in a patient in whom other causes of chronic cough have been excluded.

COPD is characterized by alveolar destruction, loss of alveolar attachments, loss of elastic recoil and increased airway resistance. This leads to limitations in expiratory flow and inadequate lung emptying upon expiration, resulting in lung hyperinflation [4]. Static hyperinflation occurs at rest and dynamic hyperinflation occurs with increased ventilation, such as during exercise [5]. Hyperinflation is usually experienced as dyspnea, and dynamic hyperinflation as dyspnea upon exertion. Patients with COPD often experience a chronic productive cough as well as significant and progressive deteriorations in lung function, peripheral muscle function, exercise capacity, activity level and quality of life (QoL) [1].

COPD is associated with several important comorbidities. These include osteoporosis, anxiety, muscle wasting and weight loss, depression, coronary artery disease (CAD), con- gestive heart failure, cancer (especially that of the lung) and pulmonary vascular disease [6]. Some of the morbidities are associated with smoking and coexist with COPD, whereas others (e.g. muscle wasting, weight loss and depression) may be associated with the pathophysiology and impact of COPD itself $[7,8]$. A significant proportion of COPD patients die from non-respiratory causes [1].

The progressive airflow limitation in COPD is due, in large part, to fibrosis and inflammation-induced narrowing in the small airways [8]. Destruction of the lung parenchyma, edema, secretions, smooth-muscle contraction and decrements in lung elastic recoil also play a part in limiting expiratory airflow. However, airflow limitation is not the only pathophysiologic mechanism at play. Abnormalities in gas exchange, primarily due to emphysema [9], are also characteristic of COPD, and can cause hypoxemia and hypercapnia. Respiratory pathogens (e.g. bacteria, atypical bacteria, viruses and fungi) are common in the lungs of patients with COPD even in the absence of respiratory symptoms, in contrast with the sterile lung environment seen in healthy lungs [8].

COPD is accompanied by inflammation in the lower airways and lung parenchyma. This inflammation is associated with abnormally high counts of neutrophils, activated macrophages, activated T lymphocytes and, sometimes, eosinophils $[1,9]$. COPD begins with a localized inflammatory response to environmental stimuli, but it is now understood to be a systemic inflammatory disease that extends beyond the lungs. The precise mechanisms of the inflammatory processes in COPD are incompletely understood. The systemic inflammation seen in COPD may result from a 'spillover' of inflammatory mediators from the airways or from independent pathways, which may include physical inactivity in 
conjunction with the metabolic syndrome, genetic abnormalities, systemic oxidative stress caused by cigarette smoking, and other factors. Systemic inflammation may be at the root of many of the extrapulmonary sequelae and associated comorbidities of COPD, such as osteoporosis and CAD [7, 8]. The multiple morbidities commonly seen in people with COPD means that the lungs should not be treated in isolation without consideration of the needs of the whole person $[6,7]$.

Historically, the fact that the airflow limitation seen in COPD is progressive and often associated with worsening debilitation has led to unjustified pessimism on the part of many physicians treating COPD [10]. In fact, appropriate treatment is associated with significant improvements in mortality, and in patient-centered outcomes such as health-related QoL, dyspnea, exercise capacity, exacerbations and hospitalizations [11]. Very limited data are available on COPD genotypes other than the important subgroup of people with COPD associated with alpha-1-antitrypsin deficiency [12]. Recent updates on COPD guidelines recommend that all individuals with COPD should be screened for this genetic subtype [1]. Recent interest has focused upon COPD phenotypes that may affect treatment decisions. These include the 'frequent exacerbators' defined by Hurst and colleagues [13] and 'hyperinflators' being studied by Celli et al [11]. How these phenotypes can be identified early in COPD is not clear, nor have studies confirmed the best therapeutic approach for either phenotype.

Over the past decade, the issue of 'mixed' obstructive lung disease (usually asthma and COPD) has been increasingly recognized $[14,15]$. However, therapy of mixed disease is beyond the scope of this review.

\section{Guidelines for COPD}

Several guidelines have been developed and published related to COPD management. These include combined North American and European guidelines [16], as well as the most widely distributed international COPD guidelines: Global Initiative for Chronic Obstructive Lung Disease (GOLD) [1]. These guidelines are based primarily on the new 2011 version of GOLD but do not alter the basic recommendations for diagnosing COPD.

Firstly COPD must be suspected or included in the differential diagnosis. Symptoms and signs such as chronic/ recurrent cough, sputum production, progressive dyspnea or functional decline due to 'breathing' problems or recurrent respiratory infections in individuals with exposure to noxious gases such as tobacco smoke should be considered as possibly due to COPD [1]. The diagnosis of COPD is based on postbronchodilator spirometry testing with a forced expiratory volume in 1 second/forced vital capacity $\left(\mathrm{FEV}_{1} / \mathrm{FVC}\right)$ ratio of less than 0.70 and an $\mathrm{FEV}_{1}$ less than $80 \%$ of predicted for the height, sex and race of the individual. Most people with symptomatic COPD, those who are candidates for therapy other than smoking cessation, usually have a $\mathrm{FEV}_{1}$ less than $70 \%$ of predicted [1].
Figure 1. Combined assessment of chronic obstructive pulmonary disease according to GOLD guidelines [1].

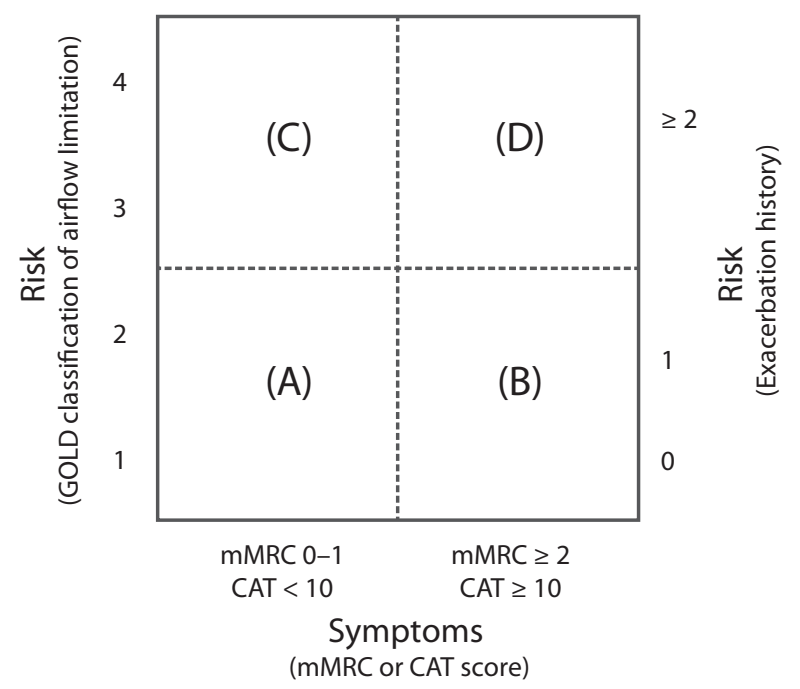

Abbreviations

CAT, COPD Assessment Test; mMRC, modified Medical Research Council Dyspnea scale

doi: 10.7573/dic.212243.f001

After confirming the diagnosis of COPD, the new guidelines can help in initiating or modifying therapy. Before the 2011 update, therapy recommendations were based primarily on lung-function values. Current treatment recommendations are based on a combination of lung function, symptoms and number of exacerbations in the previous year [1]. The new grading for COPD begins with mild (I) through to very severe (IV) stages using post-bronchodilator $\mathrm{FEV}_{1}$ and adds the impact of symptoms using the modified Medical Research Council (MRC) dyspnea scale or the COPD Assessment Test (CAT) [17] with a final additional stratification based on the number of COPD exacerbations in the previous 12 months. The final categories are A-D and fit nicely into a square (Figure 1). Not everyone will 'fit' into these four categories, but this system does recognize the fact that $\mathrm{FEV}_{1}$ alone does not predict symptoms or the prevalence of exacerbations, and is therefore not an adequate predictor of the therapeutic needs of people with COPD [1]. As with all newly developed models for the conceptualization of obstructive lung disease, this model will undoubtedly be modified over time but appears to be much more patient-oriented than the older system of mildto-very-severe classification according to $\mathrm{FEV}_{1}$ alone.

\section{Pharmacotherapy of COPD}

Pharmacological treatment can provide symptom relief, improve health status, improve exercise capacity and reduce the frequency and severity of COPD exacerbations [1]. Table 1 lists the drug combinations for COPD care that are available for inhalation via nebulizers, pressurized metered-dose inhalers (pMDIs) and dry-powder inhalers (DPIs). Combinations being tested in Phase I to Phase III clinical trials are denoted in italics. 
Table 1. Pharamcotherapy for chronic obstructive pulmonary disease.

\begin{tabular}{|c|c|}
\hline Goal & Classes of medications \\
\hline Improvement in quality of life [19-21] & $\begin{array}{l}\text { - LABAs } \\
\text { - LAMAs } \\
\text { - LABA/inhaled corticosteroid (ICS) combinations } \\
\text { - Combination LABA/ICS plus LAMAs } \\
\text { - Combination LAMA/ICS }\end{array}$ \\
\hline Improvement in exercise capacity $[1,18]$ & $\begin{array}{l}\text { - Short-acting } \beta_{2} \text {-adrenergic bronchodilators } \\
\text { - Short-acting anticholinergic bronchodilators } \\
\text { - LAMAs } \\
\text { - LABAs } \\
\text { - Combination LABA/ICS } \\
\text { - Combination LABA/LAMA } \\
\text { - Combination LAMA/ICS }\end{array}$ \\
\hline Reduction in the number of exacerbations $[1,18]$ & $\begin{array}{l}\text { - LAMAs } \\
\text { - LABAs } \\
\text { - Combination LABAs/ICS } \\
\text { - Combination LABA/LAMA } \\
\text { - Combination LAMA/ICS }\end{array}$ \\
\hline Possible reduction in age-related loss of lung function $[19,20,22,23]$ & $\begin{array}{l}\text { - LAMAs } \\
\text { - LABAs/ICS combinations } \\
\text { - Combination LABA/ICS plus LAMAs } \\
\text { - Combination LABA/LAMA } \\
\text { - Combination LAMA/ICS }\end{array}$ \\
\hline Possible increase in lifespan $[19,20,23]$ & $\begin{array}{l}\text { - LAMAs } \\
\text { - LABAs alone } \\
\text { - Combination LABA/ICS } \\
\text { - Combination LABA/LAMA } \\
\text { - Combination LAMA/ICS }\end{array}$ \\
\hline
\end{tabular}

Combinations being tested in Phase I to Phase III clinical trials are denoted in italics.

Abbreviations

LABAs, long-acting $\beta_{2}$-adrenergic bronchodilators; LAMAs, long-acting anticholinergic (or muscarinic) bronchodilators; ICS, inhaled corticosteroid doi: $10.7573 /$ dic.212243.t001

Guidelines for the treatment of patients with $\mathrm{FEV}_{1}$ less than $70 \%$ of predicted plus modest dyspnea (mMRC 0 or 1 ) (Table 2) recommend the use of one of the available longacting bronchodilators [1]. Long-acting bronchodilators are central to COPD management and are used regularly for maintenance treatment. Inhaled long-acting bronchodilators are considered to be effective and convenient [1], and include the long-acting $\beta_{2}$-agonists (LABAs) and long-acting anticholinergic (or antimuscarinic) bronchodilators (LAMAs).
LABAs act primarily to relax airway smooth muscle by stimulating $\beta_{2}$-adrenergic receptors and providing functional antagonism to bronchoconstriction [24]. The resulting bronchodilation leads to increased functional lung capacity (via lung deflation), lessening the dyspnea and the limitations placed upon the ability to undertake everyday activities $[19,21,25-27]$. LABAs have been shown to provide significant improvements in airway obstruction and outcomes (decreased symptoms and use of rescue medication, and im-

Table 2. Modified Medical Research Council dyspnea scale.

\begin{tabular}{|c|c|}
\hline Grade & Description of breathlessness \\
\hline 0 & I get breathless only with strenuous exercise. \\
\hline 1 & I get short of breath if hurrying on level ground or walking up a slight hill. \\
\hline 2 & On level ground, I walk slower than people of the same age because of breathlessness, or have to stop for breath if walking at my own pace. \\
\hline 3 & I stop for breath after walking about 100 yards or after a few minutes on level ground. \\
\hline 4 & I am too breathless to leave the house or I am breathless when dressing. \\
\hline
\end{tabular}

doi: $10.7573 /$ dic.212243.t002

Downloaded from www.drugsincontext.com Drugs in Context 2012; 212243 ISSN 1740-4398 
proved health status) $[21,28-30]$. Currently available inhaled LABAs include salmeterol and formoterol (which have a 12hour duration of effect and are administered twice daily) and indacaterol (which provides 24-hour bronchodilation with once-daily dosing). Older agents (salmeterol and formoterol) are indicated for asthma and COPD [24, 31, 32], but indacaterol (currently approved for use in more than 80 countries, including the USA) is indicated only for COPD [33].

Regular use of LABAs also results in a significant reduction in the number of exacerbations with individual LABAs compared with placebo and for LABAs overall (odds ratio [OR] 0.81 [95\% confidence interval (CI) $0.75,0.88]$ ). Donohue et al. [34] examined a database of pooled clinical-trial data (all data from studies of $\geq 12$ weeks' duration) with indacaterol, salmeterol and formoterol. They found that the incidence of worsening COPD with all LABAs was significantly lower than that seen with placebo. Similarly, the prevalence of COPD exacerbations (as an efficacy outcome) was significantly reduced with all LABAs compared with placebo [34]. LABAs provide an important means of improving the symptoms and health status of patients with COPD [19, 21, 25-27]. They may also be beneficial for reducing the number of COPD exacerbations [34], and LABA treatment is not associated with an increase in the incidence of the worsening of COPD as an adverse event. Review of safety and tolerability suggests that LABA monotherapy in patients with COPD is likely to be associated with a favorable therapeutic index [35].

A new LABA, indacaterol (Arcapta Neohaler - dry powder) was approved by the US Food and Drug Administration (FDA) in July 2011. The approved dose in the USA is $75 \mu \mathrm{g}$ once daily as a bronchodilator for patients with COPD [36, 37]. The European Medicines Agency (EMA) approved indacaterol $(150 \mu \mathrm{g}$ and $300 \mu \mathrm{g})$ in 2009 [38]. The FDA approved lower doses due to concerns related to possible adverse effects at higher doses and an apparent therapeutic plateau affect at $\approx 75 \mu$ g (i.e. the FDA believed that little additional therapeutic benefit was seen at higher doses). In the FDA review of indacaterol, its use in patients with COPD did not show worrisome findings, particularly at the lower doses of $75 \mu \mathrm{g}$ and $150 \mu \mathrm{g}$ [36]. With respect to death, intubation, and hospitalization related to asthma, COPD, or pneumonia, a meta-analysis of 23 trials and 11,755 patients with COPD found no safety signals for the $75-\mu \mathrm{g}$ and $150-\mu \mathrm{g}$ doses of indacaterol. Statistically significant improvement in the Saint George's Respiratory Questionnaire (SGRQ) used to assess COPD-specific QoL was seen with the 75- $\mu$ g dose and did not improve significantly with higher doses. Therefore, the FDA chose to approve only the 75- $\mu$ g dose in the USA. Most studies comparing once-daily and twice-daily LABAs have reported drug efficacy to be equivalent [39], but other studies have reported that indacaterol may have greater improvement in QoL as measured by the SGRQ or decreased rescue inhaler use over a 12 -week period $[17,40]$. For most COPD patients, a 12-week period is very short compared with years of medication use. Therefore, longer-term data may be helpful in determining the relative place of all of LABAs in COPD care.
Adverse cardiac side-effects (specifically arrhythmias) have been reported with long-term bronchodilator use [41, 42]. In the most recently published study using a cohort of slightly over 6000 patients, the rates of arrhythmias were elevated with LABAs and new use of short acting iatropium but not with short acting $\beta$ agonists or methylxanthines. The data used were prior to approval of long-acting anticholinergics in Canada from which the cohort of patients was identified. The rates of arrhythmias were estimated to be 1.37 events per 100 persons per year. ORs were 4.5 (95\% CI 1.4-14.4) for LABAs within the group of all individuals with arrhythmias. These data were from a relatively small group of individuals, and confirmation from larger studies is needed. Indacaterol was not included in the studies because it was also not available at the time. However, data from studies comparing all currently available LABAs showed few differences related to cardiac safety $[43,44]$.

\section{LAMAs}

Tiotropium is the first LAMA approved for once-daily therapy for COPD. Tiotropium has demonstrated significant and sustained bronchodilation (opening of the airways) [45] and reduction in hyperinflation (air trapping) [46, 47]. Tiotropium also demonstrated superior and sustained improvements in lung function $\left(\mathrm{FEV}_{1}\right)$ over ipratropium bromide (a short-acting anticholinergic medication that must be taken approximately every 4 hours). Tiotropium has also demonstrated superior improvement in key parameters of lung function over salmeterol [48]. Patients treated with tiotropium compared with those treated with placebo had less activity-induced breathlessness and improved exercise endurance. They required fewer doses of rescue medications as well as fewer exacerbations and COPD-related hospitalizations [45]. In clinical trials, the most common adverse reaction reported with tiotropium was dry mouth (which was usually mild and often resolved spontaneously during treatment) $[45,49]$. Tiotropium provided statistically significant improvements in health-related QoL as measured by the SGRQ $(p<0.001)$ and sustained improvements in lung function for up to 4 years $(p<0.001)$, but it did not alter the rate of decline in lung function. In the Understanding Potential Long-Term Impacts on Function with Tiotropium (UPLIFT) trial, tiotropium use was associated with mean delay-to-first exacerbation of 4.1 months $(p<0.001)$, and a reduction in the number of exacerbations per patient year $(14 \%, p<0.001)$. In addition, tiotropium use significantly reduced the risk of exacerbations leading to hospitalization (hazard ratio [HR] $0.86, p<0.002)$. Tiotropium use over 4 years resulted in a decrease in the risk of death (all cause and cardiac-related) of $6 \%(p=0.016)[49,50]$.

\section{LABA + LAMA therapy for COPD}

The 2011 GOLD guidelines recognized the importance of LABA + LAMA therapy, which had been shown to improve lung function and hyperinflation more than either drug alone [1]. The combination is only second-line therapy in GOLD 2011, but it is an important combination. Studies with 
COPD patients combining a LAMA and a LABA have demonstrated greater improvements in lung function (specifically $\mathrm{FEV}_{1}$ ) than either bronchodilator alone [51]. $\beta_{2}$-adrenergic receptor agonists bind to $\beta_{2}$ adrenoreceptors on the surface of smooth muscle cells at all levels of the airways (even in the small airways involved in COPD), leading directly to relaxation of smooth muscle and subsequent bronchodilation $[52,53]$. Anticholinergic agents antagonize muscarinic (M3) receptors on airway smooth muscle [52], thereby preventing smooth-muscle contraction [53]. M3 receptors mediate bronchoconstriction and mucus secretion. M3 receptors may have negative feedback on $\beta$-adrenoreceptors, which may be removed by an anticholinergic agent and thus promote the effects of the $\beta_{2}$ agonist [32]. Improved $F E V_{1}$ is an important outcome, but patients value many other outcomes more highly than $\mathrm{FEV}_{1}$. $\mathrm{FEV}_{1}$ alone does not adequately reflect the health status or QoL of a person with COPD. LABA/LAMA combination therapies demonstrate significant improvements in patient-centred outcomes such as dyspnea, symptoms, use of rescue medications and QoL compared with monotherapy with a LABA or LAMA. This information should be considered carefully when selecting COPD therapy [54].

\section{Leukotriene modifiers}

Leukotriene receptor antagonists (LTRAs) are not indicated in COPD therapy [1]. A few clinical trials have suggested that LTRAs may be an alternative to corticosteroid therapy in smokers with COPD. However, there are no data to demonstrate that LTRAs can effectively reduce the progression of inflammation in smokers with COPD [55]. Because COPD is recognized as an inflammatory disease characterized by neutrophilia (and, in some cases, eosinophilia) in sputum, hope for some role of LTRA therapy in COPD remains. Leukotriene B4, (LTB4), a neutrophil and T-cell chemo-attractant produced by macrophages, neutrophils and epithelial cells, is a potent inflammatory mediator. In cilia, and other sites of inflammation (not always LTBA-driven), there are several sites where antileukotriene agents exert their action as well as at the end-organ receptors. These drugs seem to be well tolerated, but more studies are required to demonstrate their value in COPD management before they can be recommended for use outside clinical trials [56].

\section{Methylxanthines}

Methylxanthines (e.g. theophylline, aminophylline) may be enjoying a renewed role in COPD therapy. As one of the oldest classes of therapies for obstructive lung diseases, methylxanthines have gone in and out of favor for decades. Due to its toxicity at levels close to the therapeutic range, theophylline is rarely used as a first-line COPD medication. However, in low doses that preclude the need for weekly or bi-weekly monitoring of drug levels, it has been considered to be an add-on therapy in those with severe or very severe COPD. Theophylline has been used as a modestly effective bronchodilator and reported to have anti-inflammatory properties now known to be related to its role as a histone deacetylase (HDAC) 2 enhancer [55].
Recent work has shown that low doses of theophylline enhance the activity of the key corticosteroid-associated corepressor protein HDAC2, which is reduced in COPD. Reduction of HDAC2 may be the reason for the relative corticosteroid resistance seen in COPD inflammation. This may be why combination therapy with an inhaled corticosteroid (ICS) and low-dose theophylline is beneficial in late-stage COPD treatment [57-59]. Another potential role for methylxanthines may be in controlling the fibrosis characteristic of COPD. They are very early data but new information suggests that lung fibroblasts participate in the chronic inflammation in COPD by releasing interleukin (IL)-6 and IL-8. Low-dose theophylline can alleviate the production of pro-inflammatory mediators by fibroblasts. This may bring methylxanthines back for yet another round of assessment [60].

\section{Phosphodiesterase (PDE) inhibitors}

Important new additions to the potential therapies for COPD are the oral PDE inhibitors, in particular the PDE4 inhibitor roflumilast. Roflumilast is indicated for the maintenance treatment of severe COPD ( $\mathrm{FEV}_{1}$ post-bronchodilator $<50 \%$ predicted, i.e. those in the new GOLD grades $\mathrm{C}$ and $\mathrm{D}$; see Figure 1) associated with chronic bronchitis in adult patients with a history of frequent exacerbations. The benefit of an oral medication that does not require yet another new type of inhaler technique to be taught is one of the best aspects of this new medication.

Roflumilast is to be used only as adjunct therapy in people who are already on long-term bronchodilator therapy $[1,61-$ 64]. In this specific patient population, roflumilast $(500 \mu \mathrm{g}$, once daily) reduces the prevalence of exacerbation and improves lung function [62-64]. The major role of roflumilast will probably be in the management of severe chronic bronchitis in patients who continue to have acute exacerbations despite aggressive treatment with inhaled long-acting bronchodilators (LABA + LAMA), inhaled corticosteroids and episodic 'burst' therapy with prednisone. These patients may receive most of their care in specialty clinics or offices.

Inhibition of PDE4 can increase the intracellular concentration of cyclic monophosphate (cAMP) by inhibiting its degradation, leading to reduced activity in inflammatory cells [65]. Inhibition of PDE4 can target three main components of COPD: bronchoconstriction, mucus hyper-secretion and airway remodeling [65-68]. PDE4 is the major cAMP metabolizing enzyme, so inhibition of PDE4 suppresses the inflammatory response [67]. Also, by suppressing over-expression of mucin $5 \mathrm{AC}$ by epidermal growth factor receptors, PDE4 inhibition inhibits mucus production directly [69]. Inhibition of PDE4 may also lead to minimization of airway remodeling by suppressing the release of tumor necrosis factor (TNF) $\alpha$ [70]. Though impressive, most of these data come from pre-clinical studies, and the long-term impact of roflumilast beyond the prevention of exacerbation has yet to be determined.

The use of roflumilast is limited by the specific targeted group for which it is indicated. The side-effect profile from 
clinical trials includes significant diarrhea in $6 \%$ of users and weight loss due to the diarrhea in only $2 \%$ of users, but case reports suggest a higher prevalence [71].

\section{Exacerbations}

An exacerbation is defined by GOLD as 'an acute event characterized by worsening of the patient's respiratory symptoms that is beyond normal day-to-day variations and leads to a change in medications' [1]. Exacerbations range in severity from transient declines in functional status to fatal events. Recurrent episodes of exacerbations are often associated with accelerated pulmonary decline [72] and decreased QoL [73]. Severe exacerbations are associated with an increase in the risk of mortality [74]. Less severe exacerbations (those that are amenable to treatment in a primary care office) appear to arise quickly and are responsive to therapy within 7 days, whereas more severe episodes require hospitalization with extended recovery periods. Some patients never return to their pre-exacerbation baseline [75]. Other studies have demonstrated a high prevalence of recurrence, and authors have labeled subgroups as 'frequent exacerbators' [13]. In people with severe COPD, exacerbations requiring hospitalizations result in high mortality $[76,77]$.

Bacterial and viral respiratory tract infections trigger most COPD exacerbations [78]. Additional triggers include exposure to tobacco, occupational dust, biomass fuel smoke and environmental pollution [1]. Exacerbations are more likely to recur in patient subsets with a history of exacerbations [1], patients with other independent clinical predictors (chronic cough and sputum production) [79], or in patients with physician-diagnosed concomitant asthma [80].

Exacerbations have been classified based on the number and severity of symptoms such as breathlessness, increased production of sputum and increased purulence of sputum [81], or graded based on requirements for healthcare resources such as care at home, in hospital or in the intensive care unit due to respiratory failure [82]. The numbers of exacerbations increase and become more severe with increasing COPD severity [83]. Exacerbation rates have been estimated to be 0.85 per person per year for patients with GOLD Stage 2, 1.34 for patients with GOLD Stage 3, and 2.00 for patients with GOLD Stage 4 COPD [84]. Overall, 22\% of patients with Stage 2 disease, $33 \%$ of patients with Stage 3 disease and $47 \%$ of patients with Stage 4 disease had frequent exacerbations ( $\geq 2$ in the first year of follow-up) [83]. Frequent COPD exacerbators may require different approaches than patients whose exacerbations increase in frequency based solely on increasing disease severity. Those approaches are not well outlined other than initiation of ICS earlier than usually recommended [1].

It is better to prevent exacerbations than to treat them. Smoking cessation remains the most useful approach to exacerbation prevention. In addition, avoiding environmental pollution and interaction with individuals who have viral or bacterial respiratory infections as well as appropriate immunizations (see below) are important. If patients have asthma as well as COPD, they should avoid allergic triggers such as pollen and pets [85].
Formoterol has been shown to have some significant beneficial effects compared with placebo upon outcomes defining milder exacerbations, with little difference compared with placebo for more severe exacerbations. In the large, 3 -year Towards a Revolution in COPD Health (TORCH) study, salmeterol significantly reduced the rate of all grades of exacerbations relative to placebo, including those requiring hospitalization [21]. Most other studies showed similar effects between active and placebo treatment or numerical reduction with salmeterol over placebo. In the UPLIFT trial, tiotropium was shown to decrease the time-to-first exacerbation and the number of exacerbations per year compared with placebo [49]. In a 1-year trial comparing treatment with tiotropium $(18 \mu \mathrm{g}$, once daily) with $50 \mathrm{mg}$ of salmeterol (b.i.d.) in patients with moderate-to-very-severe COPD (the POET study), tiotropium was more effective than salmeterol in preventing exacerbations [86]. Indacaterol treatment was associated with significant or numerical reductions in exacerbations compared with placebo.

ICS are commonly prescribed to patients with COPD, with reported usage ranging from 39 to $50 \%$ of patients in the USA [87, 88], 67\% in Canada [89] and 35-75\% of patients in various European countries [90-93]. COPD management strategy [1] recommends ICS treatment in patients classed as being at high risk of exacerbations, which is defined by a history of frequent exacerbations ( $\geq 2 /$ year) and/or severe airflow limitation $\left(\mathrm{FEV}_{1}<50 \%\right.$ predicted). However, the use of ICS in COPD is associated with several side-effects [94], and the risk of these side-effects may be increased by patient factors that are common in COPD, such as increasing age and multiple comorbid conditions [95]. Arguably the most serious side-effect is the increased incidence of pneumonia, which has been observed among patients with COPD in controlled clinical trials [21, 96, 97] and case-control studies [98], with an excess risk that was more pronounced with high ICS doses $(\geq 1000 \mu \mathrm{g} /$ day) [98-100]. The use of ICS without prior exacerbations appears to have an unacceptable cost-to-benefit ratio, and therefore should be used only after the risk of exacerbations has been established [101, 102].

After an exacerbation, the need for pharmacotherapy as well as pulmonary rehabilitation may change. Therefore, one must consider reassessing spirometry and inhaler technique and ascertain if the patient can cope with his/her usual environment, understands the recommended treatment regimen and/or requires long-term oxygen therapy or a home nebulizer [1].

\section{Problems in COPD management}

Often the management of COPD is suboptimal, and poor inhaler technique is one of the prime reasons for this [103106]. Physicians frequently prescribe inhaler devices based on available/preferred drugs, without ascertaining if the patient/ caregiver can use them effectively [106]. Most COPD occurs in older adults who may have comorbid conditions, such as tremor, poor eyesight, arthritis and cognitive problems that may aggravate effective inhaler device use. Therefore, device 
selection must be based on COPD severity, the physical and cognitive abilities of the patient and caregiver, the insurer's classification and requests for prior authorization, and costsaving requests from the patient.

All types of inhaler devices have similar efficacy if tested under strict clinical-trial conditions. However, in real life, each inhaler has distinct characteristics that can become advantages or disadvantages for individual patients that affect outcome, patient satisfaction (and therefore adherence for use) [104, 107, 108]. For individual patients, 'inhalers' should not be viewed as equivalent, and device type must become an important variable to consider when planning optimal COPD management [109].

Several studies have demonstrated that errors in inhaler use are common amongst patients with COPD [110, 111] (Table 3). One study estimated that while $76 \%$ of pMDI users and 49$55 \%$ of DPI users made at least one error, fortunately only $28 \%$ and $11-32 \%$ of pMDI and DPI users, respectively, made errors that compromized the clinical benefits of their medications [110]. Reasons for poor inhaler use may be divided into issues related to the device, patient, physician and healthcare professionals, practice, and cost issues leading to failure to obtain the inhalers. Multiple issues may affect any single patient.

The importance of correct use of inhaler devices in achieving optimum management of COPD cannot be overemphasized. Understanding the practical aspects of inhaler use (including device selection, correct inhalation techniques and adherence to treatment) are key to the early and successful management of COPD in the primary care setting [112]. Successful COPD management will be achieved by improving device selection based on individual patient need together with education and training of the patient, high-quality physician-patient communication and regular monitoring.

To make inhalers more patient-friendly, new inhalers continue to be produced. Indacaterol uses a new DPI that is very similar to the one used for formoterol, which can be used in individuals with very low inspiratory flow rates and which is preferred by some individuals because they feel assured they receive a 'new' dose each time [43]. One of the most recent is Respimat ${ }^{\circledR}$, and is reported to have a much 'gentler' spray that patients prefer [113]. The aerosol cloud of Respimat has a high fine-particle ratio, and the low velocity of the cloud and long 'hang' time of the aerosol can result in a larger portion of the dose being deposited in the lungs when compared with aerosols from pMDIs and DPIs. Therefore, drug formulations using Respimat may use only one-half or one-quarter of the dose delivered by a pMDI. The long duration of the spray may benefit patients who have difficulty in coordinating inhalation and device activation [114].

Unfortunately, all of the new inhalers are limited to 1-2 drugs, making it necessary for patients to continue to have multiple inhalers. Multiple inhaler types add to the problems of poor inhaler technique and unintentional poor adherence to treatment.

\section{Immunization: the forgotten pharmacotherapy}

Management of COPD includes efforts to relieve symptoms, prevent disease progression, prevent and treat exacerbations, improve exercise tolerance and improve overall QoL. Ensuring that patients with COPD are up-to-date with recommended immunizations is a primary prevention strategy that can reduce the risk for exacerbations and thereby help to improve overall QoL. Recommendations are made and updated annually by the Advisory Committee on Immunization Practices (ACIP) [115] in the USA for vaccines indicated for adults based on conditions such as COPD. Similar indications are recommended by GOLD $[1,116]$. Unfortunately, significant gaps remain in immunization coverage for those with COPD. For example, in the USA, the coverage for influenza is less than $75 \%$ [117].

Table 3. Critical inhaler errors.

\begin{tabular}{|c|c|c|c|}
\hline Critical error & pMDI & $\begin{array}{c}\text { Multi-dose DPI } \\
\text { Diskus }^{\mathrm{T} m} / \text { Turbuhaler }^{\mathrm{TM}}\end{array}$ & $\begin{array}{c}\text { Single-dose DPI } \\
\text { Handihaler }^{\mathrm{T}} / \text { Aerolizer }^{\mathrm{TM}}\end{array}$ \\
\hline Did not remove cap & $x$ & $x$ & $x$ \\
\hline Holding inhaler upside down & $x$ & $x$ & $x$ \\
\hline Did not load dose & & $x$ & $x$ \\
\hline Blowing into device & & $x$ & $x$ \\
\hline A tight seal with the lips is not made & & $x$ & $x$ \\
\hline $\begin{array}{l}\text { Inhalation and actuation not } \\
\text { synchronized }\end{array}$ & $\times$ & & \\
\hline
\end{tabular}

\section{Abbreviations}

DPI, dry-powder inhaler; pMDI, pressurized metered-dose inhaler doi: 10.7573/dic.212243.t003 
COPD exacerbations are often triggered by viral and bacterial respiratory infections. Therefore, the importance of influenza and pneumococcal immunizations for patients with COPD cannot be overemphasized. These vaccinations are recommended in COPD guidelines and included in clinical performance measures for COPD [1]. One dose of influenza vaccine is recommended annually for all adults, including those with COPD [115]. The influenza strains for the 2012-2013 season are A/California/7/2009(H1N1), A/Victoria/361/2011 (H3N2) and B/Wisconsin/1/2010 [115]. Trivalent inactivated influenza vaccine (TIV) is appropriate for all adults; a high-dose formulation is approved for persons aged 65 years or older and an intermuscular formulation is approved for those aged 18-64 years. The live attenuated influenza vaccine (LAIV) (intranasal) is seldom used for those with COPD and is approved only for adults aged up to 49 years [115].

A single dose of pneumococcal polysaccharide vaccine (PPSV23) is recommended for all adults with COPD [1]. One-time revaccination with PPSV23 is recommended for those aged 65 years and older who received a dose of PPSV23 five or more years previously and were less than 65 years of age at the time of primary vaccination. Pneumococcal conjugate vaccine (PCV13) is approved for adults in several countries, including in the USA [118], where it is recommended only as an add-on to PPSV23 vaccine for those who are immunocompromized [119].

While not specifically recommended for people with COPD, pertussis (whooping cough) immunization may be beneficial. More than 25,000 cases of pertussis were reported in the USA in 2010, and notable outbreaks have continued in several US states into 2012 [120]. Pertussis can cause serious illness in young children, teens and adults; most deaths are in infants and the elderly. Clearly, the '100-day pertussis cough' would be an unfavorable development for someone with COPD. All adults who have not received the Tdap (diphtheria, tetanus and pertussis) vaccine previously should receive a one-time dose of Tdap. Tdap can be administered regardless of the interval since the last $\mathrm{Td}$ (diphtheria) vaccine.

\section{Pulmonary rehabilitation}

Pulmonary rehabilitation is an important and inadequately used part of COPD therapy $[1,121]$. Programs should be a minimum of 6 weeks, with follow-up support, and typically include exercise training, nutrition counseling and COPD education. Pulmonary rehabilitation does not directly improve $\mathrm{FEV}_{1}$ but does address the many systemic effects of COPD. Pulmonary rehabilitation has been shown to improve exercise performance and reduce dyspnea and fatigue in COPD patients at all levels of severity. It has been shown to be especially effective if combined with tiotropium, which improves ventilation mechanics [122]. The combination results in higher exercise tolerance [1].

\section{Long-term oxygen therapy}

Chronic hypoxemia (defined as an arterial partial pressure of oxygen $\leq 55 \mathrm{mmHg}$ or increase in oxygen saturation $\leq 88 \%$ ) occurs with worsening airflow limitation [1]. In these patients, long-term oxygen therapy ( $>15$ hours per day) increases the chances of survival. Typically introduced at GOLD Stage 4 (very severe), long-term oxygen therapy may be appropriate for patients with less severe disease who have resting hypoxemia (e.g. those in category D) [1]. The benefits of long-term oxygen therapy for the hypoxic COPD patient include a mortality benefit, stabilization of pulmonary hypertension, improved mental status, reduced stay in hospital, increased exercise capacity and improved health-related QoL [1].

Patient compliance with oxygen therapy tends to be poor. Support includes education on how and why to use oxygen, and ways to overcome the self-consciousness of using a treatment that is very conspicuous [1]. Successful long-term oxygen therapy is dependent (at least in part) upon coping skills, motivation and a supportive family influence [123].

\section{Exacerbation treatment}

Exacerbations may be treated at home, in the office, in the Emergency Room, or in hospital. Home-based therapy for COPD exacerbations typically involves an increase in the dose and frequency of the existing short-acting bronchodilator therapy (especially short-acting $\beta_{2}$-adrenergic bronchodilators) [1]. Albuterol is the short-acting $\beta_{2}$-adrenergic bronchodilator of choicefor COPD exacerbations. Levalbuterol is more expensive and does not confer additional efficacy [1]. A short-acting anticholinergic bronchodilator or a combination of short-acting bronchodilators may be used for symptom control.

Most exacerbations lasting more than a few hours require systemic glucocorticosteroids [1]. Systemic glucocorticosteroids increase the rate of recovery of lung function and improve $\mathrm{FEV}_{1}$. They may also reduce the chance of treatment failure, length of hospital stay and the risk of early relapse. Typically, prednisone (30-40 mg, p.o.) is administered daily for 7-10 days. Prolonged treatment is not recommended because it increases the risk of side-effects while not providing additional efficacy $[1,13]$. Tapering of the corticosteroid dose is usually not required with short bursts lasting 10 days or less.

Respiratory infections are the most common cause of an exacerbation. There is strong evidence that patients experiencing a COPD exacerbation with signs of airway infection (e.g. increased sputum purulence) benefit from antibiotic treatment. The infectious agents in COPD can be viral or bacterial. Streptococcus pneumoniae, Hemophilus influenzae and Moraxella catarrhalis are the most common bacterial pathogens involved in COPD exacerbations.

Antibiotic selection in COPD exacerbations is important in light of evidence that inappropriate initial antimicrobial treatment contributes to exacerbations associated with mul- 
tidrug-resistant bacteria [1]. Commonly used antibiotics for treating a COPD exacerbation include $\beta$-lactams (e.g. penicillin, amoxicillin), tetracycline, doxycycline, trimethoprim/ sulfamethoxazole, macrolides (e.g. azithromycin, clarithromycin), second- or third-generation cephalosporins and fluoroquinolones (e.g. levofloxacin, moxifloxacin). Clinicians should base their choice of antibiotics on local resistance patterns (antibiogram), and therapy should be given for 3-7 days [124]. Antibiotics are used for exacerbations with any of the following criteria: increased sputum volume; increased sputum purulence; any exacerbation requiring hospitalization [1].

Details of inpatient therapy and surgical therapies [125] are beyond the scope of this review. However, a few important points should be stressed. Hospitalization may be required for therapy and control of severe resting dyspnea or new signs of severe lung impairment such as cyanosis on room air. However, hospital care may also be required due to significant exacerbations due to comorbid complications (e.g. CAD, congestive heart failure, or poorly controlled diabetes mellitus), newly occurring arrhythmias, diagnostic uncertainty (such as a need to exclude pulmonary embolism), older age and insufficient home support.

\section{Summary}

COPD is a treatable disease and therapy can improve QoL, the level of symptoms, functionality and life expectancy. Primary therapy remains removal of the toxic agent (in most cases, tobacco smoke). Additional therapy includes bronchodilators ( $\beta$-adrenergic and antimuscarinic classes). ICS are used to prevent exacerbations and, in carefully selected patients, may have additional benefits due to exacerbation prevention. Long-acting bronchodilators also reduce the risk of exacerbations. Pulmonary rehabilitation, immunizations and, in very severe COPD, long-term oxygen therapy are the conventional COPD therapies. However, COPD is a systemic disease and often requires therapy of its protean-associated morbidities from depression to osteoporosis and muscle-wasting. Despite pessimism from several quarters, COPD is treatable.

\section{Research needs (author's opinion)}

As with all common chronic diseases, the opportunities to improve the understanding and management of COPD are numerous. We have limited understanding of COPD with regard to inflammatory cells, inflammatory triggers; the role of each step in the inflammatory cascade; the physiology of parenchyma destruction, hyperinflation and formation of blebs and bullae; and the role of genes, epigenetics and phenotypes.

Some large and lengthy randomized controlled trials have been completed, but they identified almost as many questions as they answered. It remains unclear whether it is better to begin LABAs or LAMAs or a combination of the two, or if therapy should be targeted to the few phenotypes we have identified to date. The recommended medication hierarchy in the GOLD guidelines relies on research evidence from very short-term 12 -week studies and significant expert opin- ion. That expert opinion is usually from pulmonologists and respirologists who treat the later stages of COPD. Their perspectives may not reach the same level of 'expertise' for less severe COPD seen in primary-care practices.

Opportunities for clinical research in primary care are also numerous. Tools recommended in the GOLD guidelines designed to help convert recommendations into everyday practice give preference to the mMRC and CAT without explaining why tools developed and validated in primary care have been excluded [126]. 'Natural history' studies are required to help determine the optimal frequency for COPD assessment with tools such as the BODE index, the mMRC and spirometry.

Researchers have yet to demonstrate the outcome benefits of early diagnosis in asymptomatic COPD or how to best recognize symptomatic COPD prior to significant changes in functional status. Do we screen for COPD and, if so, how? We have not had long-term studies that assessed whether specific inhaler types improve outcomes or even if once-daily medications are associated with better outcomes than those requiring multiple daily doses.

Reporting of the high prevalence of multiple morbidities in people with COPD has outlined several new areas of investigation. Are there clusters or 'phenotypes' of COPD associated with specific clusters of morbidities? Guidelines exist for COPD and most of the individual morbidities, but how should those guidelines be modified for people with multiple conditions? The 2011 GOLD guidelines began the discussion but made limited progress [1]. How is the systemic inflammation of COPD related to comorbidities such as osteoporosis, muscle-wasting and depression? What protects the one-third to one-half of chronic smokers who never develop COPD? Can we identify who will and will not develop COPD? Can we use this knowledge to help prevent COPD in others who are susceptible?

The opportunities do not stop with biomedical researchers, scientists and clinical/health services researchers. We need workers in biophysics and bioengineering sectors to design better drug-delivery devices, delivering new and old drugs more effectively to the lungs (and perhaps even to the subsections of the lungs). Additional devices and delivery systems are needed to introduce one-way valves to deflate large areas of hyperinflation. Imaging techniques are advancing, but many methods introduce larger doses of radiation than is optimal for already damaged lungs.

The opportunities are unlimited but the funds are not. As COPD moves into third place amongst the most common causes of death in the world, the need for new basic-science information, therapies and delivery systems will increase. For now we have to work with the information and therapies we have, knowing that the understanding and management of COPD has improved significantly in the past 10 years, but we still have a long way to go.

\section{Funding}

The Author received an honorarium from the Publisher. 


\section{References}

1. Global Initiative for Chronic Obstructive Lung Disease. Global strategy for the diagnosis, management, and prevention of COPD, 2011. Available at: www.goldcopd. org. [Last accessed: 19 October 2012].

2. Center for Disease Control and Prevention. Deaths: preliminary data for 2009. National Vital Statistics Reports 2011:59:4. Available at: www.cdc.gov/nchs/nvss.htm. [Last accessed: 19 October 2012].

3. World Health Organization. Chronic respiratory diseases. Chronic obstructive pulmonary disease 2011. Available at: who.int/respiratory/copd/en/. [Last accessed: 19 October 2012].

4. O'Donnell DE. Hyperinflation, dyspnea, and exercise intolerance in chronic obstructive pulmonary disease. Proc Am Thorac Soc 2006;3:180-4.

5. O'Donnell DE Dynamic lung hyperinflation and its clinical implication in COPD. Rev Mal Respir 2008;25:1305-18.

6. Yawn B. Differential assessment and management of asthmas vs. chronic obstructive pulmonary disease. Medscape J Med 2009;11:20.

7. Fabbri LM, Luppi F, Beghe B, Rabe KF. Complex chronic comorbidities of COPD. Eur Respir J 2008;31:204-12.

8. Friedlander AL, Lynch D, Dyar LA, Bowler RP. COPD phenotypes of chronic obstructive pulmonary disease. COPD 2007;2:45-68.

9. Stockley RA, O’Brien C, Pye A, Hill SL. Relationship of sputum color to nature and outpatient management of acute exacerbations of COPD. Chest 2009;136(5 Suppl):e30.

10. Yawn BP, Wollan PC. Knowledge and attitudes of family physicians coming to COPD continuing medical education. Int J Chron Obstruct Pulmon Dis 2008;3:311-17.

11. Celli B, Cross S, Grossman R et al. Improving the care of COPD patients - suggested action points by the COPD exacerbations taskforce for reducing the burden of exacerbations of COPD. Prim Care Respir J 2006;15:139-42.

12. Krowka MJ. Breathing Easier: Early Identification of COPD and Alpha-1 Antitrypsin Deficiency. Available at: http://www.medscape.org/viewarticle/726819 [Last accessed: 31 October 2012].

13. Hurst JR, Donaldson GC, Quint JK et al. Temporal clustering of exacerbations in chronic obstructive pulmonary disease. Am J Respir Crit Care Med 2009;179:369-74.

14. Miravitlles M, Andreu I, Romero Y, Sitjar S, Altés A, Anton E. Difficulties in differential diagnosis of COPD and asthma in primary care. Br J Gen Pract 2012;62:e68-e75.

15. Kim TB, Oh YM, Chang YS et al. The reality of an intermediate type between asthma and COPD in practice. Respir Care 2012;57:1248-53.

16. Qaseem A, Wilt TJ, Weinberger SE et al. Diagnosis and management of stable chronic obstructive pulmonary disease: a clinical practice guideline update from the American College of Physicians, American Col- lege of Chest Physicians, American Thoracic Society, and European Respiratory Society. Ann Intern Med 2011;155(3):179-91.

17. Jones PW, Mahler DA, Gale R, Owen R, Kramer B. Profiling the effects of indacaterol on dyspnoea and health status in patients with COPD. Respir Med 2011;105:892-9.

18. Celli BR, MacNee W. Standards for the diagnosis and treatment of patients with COPD: a summary of the ATS/ERS position paper. Eur Respir J 2004;23:932-46.

19. Tashkin DP, Celli B, Senn S et al. A 4-year trial of tiotropium in chronic obstructive pulmonary disease. $\mathrm{N}$ Engl J Med 2008;359:1543-54.

20. Karner C, Cates CJ. Combination inhaled steroid and long-acting beta ${ }_{2}$-agonist in addition to tiotropium versus tiotropium or combination alone for chronic obstructive pulmonary disease. Cochrane Database Syst Rev 2011(3):CD008532.

21. Calverley PM, Anderson JA, Celli B et al. Salmeterol and fluticasone propionate and survival in chronic obstructive pulmonary disease. N Engl J Med 2007;22;356:775-89.

22. Celli BR, Thomas NE, Anderson JA et al. Effect of pharmacotherapy on rate of decline of lung function in chronic obstructive pulmonary disease: results from the TORCH study. Am J Respir Crit Care Med 2008;178:332-8.

23. Decramer M, Celli B, Kesten S, Lystig T, Mehra S, Tashkin DP. Effect of tiotropium on outcomes in patients with moderate chronic obstructive pulmonary disease (UPLIFT): a prespecified subgroup analysis of a randomised controlled trial. Lancet 2009;374:1171-8.

24. Norris SL, Yen PY, Dana TL, Care BR, Burda BU. Drug class review: beta 2 -agonists. Oregon Health and Science University, Portland, 2006.

25. Calverley PM. New options for bronchodilator treatment in COPD. Thorax 2010;65:468-9.

26. Hanania NA, Sharafkhaneh A, Celli B et al. Acute bronchodilator responsiveness and health outcomes in COPD patients in the UPLIFT trial. Respir Res 2011;12:6.

27. O'Donnell DE, Webb KA. The major limitation to exercise performance in COPD is dynamic hyperinflation. J Appl Physiol 2008;105:753-5.

28. Brienza NS, Amor-Carro O, Ramos-Barbon D: An update on the use of indacaterol in patients with COPD. Ther Adv Respir Dis 2011;5:29-40.

29. Rodrigo GJ, Nannini LJ, Rodriguez-Roisin R. Safety of long-acting beta-agonists in stable COPD: a systematic review. Chest 2008;133:1079-87.

30. Tashkin DP, Fabbri LM. Long-acting beta-agonists in the management of chronic obstructive pulmonary disease: current and future agents. Respir Res 2010;11:149.

31. Allen and Hanburys Limited. Serevent Accuhaler, Serevent Diskus, Serevent Evohaler. Summary of product characteristics. Available at: www.medicines.org.uk/ 
EMC/searchresults.aspx?term=serevent. [Last accessed: 19 October 2012.

32. Novartis Pharmaceuticals UKLimited. Foradil: summary of product characteristics. Available at: www.medicines. org.uk/EMC/searchresults.aspx?term=foradil. [Last accessed: 19 October 2012].

33. Novartis Pharmaceuticals UK Limited. Onbrez Breezhaler 150 and 300 microgram inhalation powder, hard capsules. UK Summary of Product Characteristics. Available at: www.medicines.org.uk/EMC/searchresults. aspx?term=onbrez. [Last accessed: 19 October 2012].

34. Donohue JF, Singh D, Kornmann O, Lawrence D, Lassen C, Kramer B. Safety of indacaterol in the treatment of patients with COPD. Int J Chron Obstruct Pulmon Dis 2011;6:477-92.

35. Yawn B, Kleerup E, Zhang J, Kianifard F, Williams J. Inhaled corticosteroid use and GOLD severity stage among patients with chronic obstructive pulmonary disease in different regions. Am J Respir Crit Care Med 2012 [in press].

36. Chowdhury BA, Seymour SM, Michele TM, Durmowicz AG, Liu D, Rosebraugh CJ. The risks and benefits of indacaterol - the FDA's review. N Engl J Med 2011;365:2247-9.

37. FDA approved drug products: Arcapter Neohaler (indacaterol maleate). Food and Drug Administration, Silver Spring. Available at: www.accessdata.fda.gov/ drugsatfda_docs/nda/2011/022383Orig1s000SumR. pdf. [Last accessed: 19 October 2012].

38. Human medicines: Onbrez Breezhaler (indacaterol). European Medicine Agency, London. Available at: http://www.ema.europa.eu/ema/index.jsp?curl=pages/ medicines/human/medicines/001114/human_ med_001219.jsp\&murl=menus/medicines/medicines. jsp\&mid=WC0b01ac058001d124. [Last accessed: 19 October 2012].

39. Cope S, Capkun-Niggli G, Gale R et al. Efficacy of oncedaily indacaterol relative to alternative bronchodilators in COPD: a patient-level mixed treatment comparison. Value Health 2012;15:524-33.

40. Korn S, Kerwin E, Atis S, Amos C, Owen R, Lassen C. Indacaterol once-daily provides superior efficacy to salmeterol twice-daily in COPD: a 12-week study. Respir Med 2011;105:719-26.

41. Cave AC, Hurst MM. The use of long acting $\beta_{2}$-agonists, alone or in combination with inhaled corticosteroids, in chronic obstructive pulmonary disease (COPD): a risk-benefit analysis. Pharmacol Ther 2011;130:11443.

42. Wilchesky M, Ernst P, Brophy JM, Platt R, Suissa $S$. Bronchodilator use and the risk of arrhythmia in COPD. Parts 1 and 2. Chest 2012;142-298-309.

43. No authors listed. Indacaterol. A long-acting beta-2 agonist, no advantages in COPD. Prescrire Int 2011; 20:201-5.

44. Worth H, Chung KF, Felser JM, Hu H, Rueegg P. Cardio- and cerebrovascular safety of indacaterol vs for- moterol, salmeterol, tiotropium and placebo in COPD. Respir Med 2011;105:571-9.

45. Casaburi R, Mahler DA, Jones PW et al. A longterm evaluation of once-daily inhaled tiotropium in chronic obstructive pulmonary disease. Eur Respir J 2002;1:217-24.

46. Celli B, ZuWallack R, Wang $S$ et al. Improvement in resting inspiratory capacity and hyperinflation with tiotropium in COPD patients with increased static lung volumes. Chest 2003;124:1743-8.

47. O'Donnell DE, Fluge T, Gerken $F$ et al. Effects of tiotropium on lung hyperinflation, dyspnoea and exercise tolerance in COPD. Eur Respir J 2004;23:832-48.

48. Brusasco V, Hodder R, Miravitlles $M$ et al. Health outcomes following treatment for six months with once daily tiotropium compared with twice daily salmeterol in patients with COPD. Thorax 2003;58: 399-404.

49. Tashkin D, Celli B, Kesten S, Lystig T, Decramer M. Effect of tiotropium in men and women with COPD: results of the 4-year UPLIFT trial. Respir Med 2010;104:1495-504.

50. Celli B, Decramer M, Kesten S, Liu D, Mehra S, Tashkin DP. Mortality in the 4-year trial of tiotropium (UPLIFT) in patients with chronic obstructive pulmonary disease. Am J Respir Crit Care Med 2009;180:948-955.

51. Sethi S, Cote C. Bronchodilator combination therapy for the treatment of chronic obstructive pulmonary disease. Curr Clin Pharmacol 2011;6:48-61.

52. Barnes PJ. Distribution of receptor targets in the lung. Proc Am Thorac Soc 2004;1:345-51.

53. Rennard SI. Combination bronchodilator therapy in COPD. Chest 1995;107(5 Suppl):171S-175S.

54. van der Molen T, Cazzola M. Beyond lung function in COPD management: effectiveness of LABA/LAMA combination therapy on patient-centred outcomes. Prim Care Respir J 2012;21:101-8.

55. Tamimi A, Serdarevic D, Hanania NA. The effects of cigarette smoke on airway inflammation in asthma and COPD: therapeutic implications. Respir Med 2012;106:319-28.

56. Drakatos P, Lykouras D, Sampsonas F, Karkoulias K, Spiropoulos K. Targeting leukotrienes for the treatment of COPD? Inflamm Allergy Drug Targets 2009;8:297306.

57. Ford PA, Durham AL, Russell RE, Gordon F, Adcock IM, Barnes PJ. Treatment effects of low-dose theophylline combined with an inhaled corticosteroid in COPD. Chest 2010;137:1338-44.

58. Zhang WH, Zhang Y, Cui YY et al. Can Beta2-adrenoceptor agonists, anticholinergic drugs, and theophylline contribute to the control of pulmonary inflammation and emphysema in COPD? Fundam Clin Pharmacol 2012; 26:118-34.

59. Voduc N, Alvarez GG, Amjadi K, Tessier C, Sabri E, Aaron SD. Effect of theophylline on exercise capacity in COPD patients treated with combination long-acting 
bronchodilator therapy: a pilot study. Int J Chron Obstruct Pulmon Dis 2012;7:245-52.

60. Zhang J, Feng MX, Qu JM. Low dose theophylline showed an inhibitory effect on the production of IL-6 and IL-8 in primary lung fibroblast from patients with COPD. Mediators Inflamm 2012:492901.

61. Hatzelmann A, Morcillo E, Lungarella G et al. The preclinical pharmacology of roflumilast - a selective, oral phosphodiesterase 4 inhibitor in development for chronic obstructive pulmonary disease. Pulm Pharmacol Ther 2010;23;235-56.

62. Calverley P, Rabe K, Goehring U-M et al. Roflumilast in symptomatic chronic obstructive pulmonary disease: two randomised clinical trials. Lancet 2009;374:68594.

63. Fabbri L, Calverley P, Izquierdo-Alonso J et al. Roflumilast in moderate-to-severe chronic obstructive pulmonary disease treated with longacting bronchodilators: two randomised clinical trials. Lancet. 2009;374:695-703.

64. Rabe K. Update on roflumilast, a phosphodiesterase 4 inhibitor for the treatment of chronic obstructive pulmonary disease. Brit J Pharmacol 2011;163:53-67.

65. Essayan DM. Cyclic nucleotide phosphodiesterases. J Allergy Clin Immunol 2001;108:671-80.

66. Compton C, Gubb J, Nieman R et al. Cilomilast, a selective phosphodiesterase-4 inhibitor for treatment of patients with chronic obstructive pulmonary disease: a randomised, dose-ranging study. Lancet 2001;358:26570.

67. Soto FJ, Hanania NA. Selective phosphodiesterase-4 inhibitors in chronic obstructive lung disease. Curr Opin Pulm Med 2005;11:129-34.

68. Sturton G, Fitzgerald M. Phosphodiesterase 4 inhibitors for the treatment of COPD. Chest 2002;121:192S196S.

69. Mata M, Sarria B, Buenestado A et al. Phosphodiesterase 4 inhibition decreases MUC5AC expression induced by epidermal growth factor in human airway epithelial cells. Thorax 2005;60:144-52.

70. Profita M, Chiappara G, Mirabella F et al. Effect of cilomilast (Ariflo) on TNF-alpha, IL-8, and GM-CSF release by airway cells of patients with COPD. Thorax 2003;58:573-9.

71. Pullen E. Roflumilast: How Much is it Worth to Avoid an Exacerbation of Chronic Bronchitis? Available at: http://drpullen.com/roflumilast [Last accessed: 31 October 2012].

72. Donaldson GC, Seemungal TA, Bhowmik A, Wedzicha JA. Relationship between exacerbation frequency and lung function decline in chronic obstructive pulmonary disease. Thorax 2002;57:847-52.

73. Seemungal TA, Donaldson GC, Paul EA et al. Effect of exacerbation on quality of life in patients with chronic obstructive pulmonary disease. Am J Respir Crit Care Med 1998;157:1418-22.

74. Soler-Cataluña JJ, Martinez-Garcia MÁ, Román Sánchez $\mathrm{P}$ et al. Severe acute exacerbations and mortality in patients with chronic obstructive pulmonary disease. Thorax 2005;60:925-31.

75. Seemungal TA, Donaldson GC, Bhowmik A, Jeffries DJ, Wedzicha JA. Time course and recovery of exacerbations in patients with chronic obstructive pulmonary disease. Am J Respir Crit Care Med 2000;161:1608-13.

76. Ai-Ping C, Lee KH, Lim TK. In-hospital and 5-year mortality of patients treated in the ICU for acute exacerbation of COPD: a retrospective study. Chest 2005;128:518-24.

77. Patil SP, Krishnan JA, Lechtzin N, Diette GB. Inhospital mortality following acute exacerbations of chronic obstructive pulmonary disease. Arch Intern Med 2003;163:1180-6.

78. Papi A, Bellettato CM, Braccioni $\mathrm{F}$ et al. Infections and airway inflammation in chronic obstructive pulmonary disease severe exacerbations. Am J Respir Crit Care Med 2006;173:1114-21.

79. Burgel PR, Nesme-Meyer P, Chanez P et al. Cough and sputum production are associated with frequent exacerbations and hospitalizations in COPD subjects. Chest 2009;135:975-82.

80. Wan ES, DeMeo DL, Hersh CP et al. Clinical predictors of frequent exacerbations in subjects with severe chronic obstructive pulmonary disease (COPD). Respir Med 2011;105:588-94.

81. Anthonisen NR, Manfreda J, Warren CP et al. Antibiotic therapy in exacerbations of chronic obstructive pulmonary disease. Ann Intern Med 1987;106:196-204.

82. American Thoracic Society, European Respiratory Society. Standards for the diagnosis and management of patients with COPD. New York/Lausanne. 20 October 2011. Available at: www.copd-ats-ers.org/copddoc.pdf. [Last accessed: 19 October 2012].

83. Hurst JR, Vestbo J, Anzueto A et al. Susceptibility to exacerbation in chronic obstructive pulmonary disease. N Engl J Med. 2010;363:1128-38.

84. Donaldson GC, Wedzicha JA. COPD exacerbations.1: epidemiology. Thorax 2006;61:164-8.

85. Roy A, Wisnivesky JP. Comprehensive use of environmental control practices among adults with asthma and COPD. Allergy Asthma Proc 2010;31:72-7.

86. Vogelmeier C, Hederer B, Glaab T et al. Tiotropium versus Salmeterol for the Prevention of Exacerbations of COPD. N Engl J Med 2011;364:1093-1103.

87. Drummond MB, Dasenbrook EC, Pitz MW, Murphy DJ, Fan E. Inhaled corticosteroids in patients with stable chronic obstructive pulmonary disease: a systematic review and meta-analysis. JAMA 2008;300:2407-16 [Erratum in: JAMA 2009;11;301:1024].

88. Asche CV, Brixner DI, Conoscenti CS, Young DC, Shah $\mathrm{H}$, Phillips A. Assessment of physician prescribing for primary care patients with chronic obstructive pulmonary disease (COPD) in a national electronic medical record (EMR) research database. Chest 2006;130:supplement $175 S$ [abstract]. 
89. Bourbeau J, Sebaldt RJ, Day A et al. Practice patterns in the management of chronic obstructive pulmonary disease in primary practice: the CAGE study. Can Respir J 2008;15:13-19.

90. de Miguel-Díez J, Carrasco-Garrido P, Rejas-Gutierrez $\mathrm{J}$ et al. Inappropriate overuse of inhaled corticosteroids for COPD patients: impact on health costs and health status. Lung 2011;189:199-206.

91. Cazzola M, Segreti A, Bettoncelli G et al. Change in asthma and COPD prescribing by Italian general practitioners between 2006 and 2008. Prim Care Respir J 2011;20:291-8.

92. Mehuys E, Boussery K, Adriaens E et al. COPD management in primary care: an observational, community pharmacy-based study. Ann Pharmacother 2010;44:257-66.

93. Smith CJ, Gribbin J, Challen KB, Hubbard RB. The impact of the 2004 NICE guideline and 2003 General Medical Services contract on COPD in primary care in the UK. QJM 2008;101:145-53.

94. Singh S, Loke YK. An overview of the benefits and drawbacks of inhaled corticosteroids in chronic obstructive pulmonary disease. Int J Chron Obstruct Pulmon Dis 2010;5:189-95.

95. Patel AR, Hurst JR. Extrapulmonary comorbidities in chronic obstructive pulmonary disease: state of the art. Expert Rev Respir Med 2011;5:647-62.

96. Kardos P, Wencker M, Glaab T, Vogelmeier C. Impact of salmeterol/fluticasone propionate versus salmeterol on exacerbations in severe chronic obstructive pulmonary disease. Am J Respir Crit Care Med 2007;175:144-9.

97. Wedzicha JA, Calverley PM, Seemungal TA et al. The prevention of chronic obstructive pulmonary disease exacerbations by salmeterol/fluticasone propionate or tiotropium bromide. Am J Respir Crit Care Med 2008;177:19-26.

98. Ernst P, Gonzalez AV, Brassard P, Suissa S. Inhaled corticosteroid use in chronic obstructive pulmonary disease and the risk of hospitalization for pneumonia. Am J Respir Crit Care Med 2007;176:162-6.

99. Crim C, Calverley PM, Anderson JA et al. Pneumonia risk in COPD patients receiving inhaled corticosteroids alone or in combination: TORCH study results. Eur Respir J 2009;34:641-7.

100. Joo MJ, Au DH, Fitzgibbon ML, Lee TA. Inhaled corticosteroids and risk of pneumonia in newly diagnosed COPD. Respir Med 2010;104:246-52.

101. Chen S, Plauschinat CA, Wu N, Fraser K, Boulanger L. Economic impact of using inhaled corticosteroids without prior exacerbation among elderly patients with chronic obstructive pulmonary disorder. J Med Econ 2011;14:458-62.

102. Wang J, Nie B, Xiong W, Xu Y. Effect of long-acting beta-agonists on the frequency of COPD exacerbations: a meta-analysis. J Clin Pharm Ther 2012;37:204-11.

103. Dolovich MB, Ahrens RC, Hess DR et al. Device selection and outcomes of aerosol therapy: Evidence-based guidelines: American College of Chest Physicians/ American College of Asthma, Allergy, and Immunology. Chest 2005;127:335-71.

104. Melani AS, Bonavia M, Cilenti V et al. Inhaler mishandling remains common in real life and is associated with reduced disease control. Respir Med 2011;105:930-8.

105. Rootmensen GN, van Keimpema AR, Jansen HM, de Haan RJ. Predictors of incorrect inhalation technique in patients with asthma or COPD: a study using a validated videotaped scoring method. J Aerosol Med Pulm Drug Deliv 2010;23:323-8.

106. Nikander K. Challenges and opportunities in respiratory drug delivery devices. Expert Opin Drug Deliv 2010;7:1235-8.

107. Bourbeau J, Bartlett SJ. Patient adherence in COPD. Thorax 2008;63:831-8.

108. Hodder R, Price D, Schulte M et al. Patient preferences for inhaler devices in chronic obstructive pulmonary disease: experience with Respimat Soft Mist inhaler. Int J Chron Obstruct Pulmon Dis 2009;4:381-90.

109. Chapman KR, Voshaar TH, Virchow JC. Inhaler choice in primary practice. Eur Respir Rev 2005;14:117-22.

110. Molimard M, Raherison C, Lignot S, Depont F, Abouelfath A, Moore N. Assessment of handling of inhaler devices in real life: an observational study in 3811 patients in primary care. J Aerosol Med 2003;16:24954.

111. Fink JB, Rubin BK. Problems with inhaler use: a call for improved clinician and patient education. Respir Care 2005;50:1360-74.

112. Yawn BP. Optimizing chronic obstructive pulmonary disease management in primary care. South Med J 2011;104:121-7.

113. Anderson P. Use of Respimat Soft Mist inhaler in COPD patients. Int J Chron Obstruct Pulmon Dis 2006;1:251-9.

114. Dalby RN, Eicher J, Zierenberg B. Development of Respimat ${ }^{\circledR}$ Soft Mist ${ }^{\mathrm{TM}}$ Inhaler and its clinical utility in respiratory disorders. Available at: http://www.dovepress. $\mathrm{com} /$ development-of-respimatreg-soft-misttrade-inhaler-and-its-clinical-uti-peer-reviewed-article-MDER [Last accessed: 31 October 2012].

115. CDC. Prevention and control of influenza with vaccines: recommendations of the Advisory Committee on Immunization Practices (ACIP) - United States, 2012-2013 influenza season. MMWR Wkly Rep 2012;61:613-618.

116. Poland G. A global prescription for adult immunization: time is catching up with us. Vaccine 2010;28: 7137-9.

117. CDC. Final state-level influenza vaccination coverage estimates for the 2010-2011 season - United States, National Immunization Survey and Behavioral Risk Factor Surveillance System, August 2010 through May 2011. Available at: www.cdc.gov/flu/professionals/vaccination/coverage_1011 estimates.htm. [Last accessed: 19 October 2012]. 
118. CDC. Licensure of 13-valent pneumococcal conjugate vaccine for adults aged 50 years and older. MMWR Wkly Rep 2012;21:394-5.

119. Accessed at: http://www.cdc.gov/vaccines/vpd-vac/ pneumo/in-short-both.htm\#who [Last accessed: 13 November 2012].

120. CDC. Pertussis (whooping cough). Accessed at: www. cdc.gov/pertussis/index.html. [Last accessed: 19 October 2012].

121. Burns N. COPD and pulmonary rehabilitation. Aust Fam Physician 2012;41:460.

122. Casaburi R, Kukafka D, Cooper CB et al. Improvement in exercise tolerance with the combination of tiotropium and pulmonary rehabilitation in patients with COPD. Chest 2005;127:809-17
123. Güell, Rous R. Long-term oxygen therapy: are we prescribing appropriately? Int J Chron Obstruct Pulmon Dis 2008;3:231-7.

124. Boersma WG. Antibiotics in acute exacerbations of COPD: the good, the bad and the ugly. Eur Respir J 2012; $40: 1-3$.

125. Hogg JC, Chu FS, Tan WC et al. Survival after lung volume reduction in chronic obstructive pulmonary disease: insights from small airway pathology. Am J Respir Crit Care Med 2007;176:454-9.

126. van der Molen T, Willemse BWM, Schokker S, ten Hacken N, Postma DS, Juniper EF. Development, validity and responsiveness of the Clinical COPD Questionnaire. Health Qual Life Outcomes 2003;1:13. 